\title{
Invisibility of Racial/Ethnic Minorities in Developmental Science: Implications for Research and Institutional Practices
}

\author{
Moin Syed \\ University of Minnesota, USA \\ Carlos Santos \\ Arizona State University, USA \\ Hyung Chol (Brandon) Yoo \\ Arizona State University, USA \\ Linda P. Juang \\ University of Potsdam, Germany \\ In Press \\ American Psychologist: \\ "New Directions in Developmental Science with Marginalized Youth.”
}

Version Date: 12/15/17

Contact:moin@umn.edu,carlos.e.santos@asu.edu,yoo@asu.edu,juang@uni-potsdam.de 


\begin{abstract}
García Coll and colleagues’ (1996) integrative model was a landmark paper for developmental science, and psychology more broadly, in outlining the multitude of social and cultural factors at play when seeking to understand the development of racial/ethnic minority children. The time is ripe to not only take stock of those advances, but also to evaluate the integrative model in the context of present-day research practice within developmental psychology, and psychology more broadly. The purpose of this article is to bring a systemic perspective to developmental science through a discussion of current practices in the field. To do so, we examine invisibility, or how dominant practices serve to overlook, silence, or dismiss knowledge produced by and for racial/ethnic minority populations. Guided by the interpretive framework of intersectionality (Crenshaw, 1991) we discuss three key questions: From whose vantage point is research conducted? What types of questions are valued? And who gets left out? We then conclude with recommendations for changes in practices for individuals, institutions, and the field at large. Importantly, whereas our analysis is largely grounded in research and practices in developmental psychology, it is also highly relevant to psychological science as a whole.
\end{abstract}

Keywords: Developmental Psychology, Race/Ethnicity, Intersectionality, Invisibilities 
The historical exclusion of racial/ethnic minorities from the science of psychology has been well-documented (Graham, 1992; Richards, 1997; Winston, 2004). Developmental psychologists have been on the forefront of attempts to rectify this disparity in research focus, bringing attention to the conditions, circumstances, and life experiences of racial/ethnic minority children and adolescents. García Coll and colleagues’ (1996) integrative model for the study of developmental competencies in minority children is one of the most influential scholarly works in this regard, as it outlined the multitude of social and cultural factors at play when seeking to understand the development of minority children. Since the development of this model, there has been an increase in the breadth and sophistication of research on the development of racial/ethnic minority children (Quintana et al., 2006), covering such topics as how character strengths (e.g., ethnic identity; Umaña-Taylor et al., 2014) and promotive environments (e.g., racial socialization; Hughes et al., 2006), among many other topics, can facilitate positive development.

It is clear that there have been advances in understanding the contexts of racial/ethnic minority development in terms of the subjects of our research. There have not been concomitant advances, however, in understanding developmental psychology, or psychology more broadly, from a systemic perspective. That is, not only have racial/ethnic minority individuals been historically excluded from research studies, but their presence and perspectives have often been excluded from the ranks of those doing the research, perpetuating a sense of invisibility within the field.

The purpose of the present analysis is to raise attention to this invisibility by bringing a systemic perspective to developmental science. Our analysis is guided by merging the integrative model with the interpretive framework of intersectionality (Crenshaw, 1991), which draws attention to how social structures create and maintain multiple forms of overlapping oppression (see also Cole, 2009). This merger leads us to discuss three key questions for developmental science: From whose vantage point is research conducted? What types of questions are valued? And who gets left 
out? We grapple with these questions while reflecting on the content and promise of the integrative model and consider if, how, and why it has or hasn't moved the field of developmental science to be more inclusive. We then conclude with recommendations for changes in practices for individuals, institutions, and the field at large that correspond to these three questions. Our primary intent in this paper is to draw attention to important systemic concerns and raise awareness among the psychology community. We hope to get readers thinking as opposed to providing firm answers or resolutions to these very complex issues. Importantly, whereas our analysis is largely grounded in research and practices in developmental psychology, it is also relevant to psychological science as a whole and thus draws from other areas of psychology.

\section{The Integrative Model in a Systemic Context}

The genesis of the integrative model for the study of developmental competencies in minority children (García Coll et al., 1996) was motivated by the fact that existing models of development, even models considered to be “contextual,” failed to adequately account for the unique experiences of racial/ethnic minority youth (e.g., Bronfenbrenner, 1979). Accordingly, the integrative model specifies three families of factors--social position (race, ethnicity, social class, gender), social stratification mechanisms (racism in all its forms), and segregation (residential, economic, social, and psychological)--as constituting a set of factors that the authors described as “non-shared” with racial/ethnic majority populations. These factors have a causal influence on developmental competencies through their effect on the "shared” factors of promoting and inhibiting environments, adaptive culture, child factors, and family factors. Although García Coll et al. (1996) made a clear distinction between the non-shared and shared factors, in reality all of the factors are shared, but the non-shared factors disproportionately impact minority youth in a negative way. Indeed, the lack of attention to these non-shared factors was the impetus for the development of the model, indicating that even though they are more accurately conceptualized as shared, they 
had not been treated as centrally important in work with majority youth. The model clearly struck a chord with a new generation of scholars seeking a more inclusive developmental science, as is evident from the current special issue commemorating the 20th anniversary of the article.

Our primary purpose is not to evaluate the wealth of research inspired by the integrative model, but to expand and apply the model to a new problem. Fitting with the disciplinary emphasis of psychology, the model was intended to serve as a framework for understanding individual-level processes within the US sociocultural context. Nevertheless, we argue that the model can also be used to understand the broader context in which developmental science itself has been conducted. That is, the model can be used to advance a systemic understanding as well as an individual one. Conducting a systemic analysis of developmental science, however, requires additional concepts and analytic tools beyond what was included in the original integrative model.

\section{Expanding the Conceptual Terrain of the Integrative Model: The Ideological Setting of}

\section{Developmental Science}

Psychology as a discipline is defined by its focus on individual organisms. Although there are some sub-disciplines such as areas of social, organizational, and community psychology that have a richer tradition of moving beyond the individual to examine structural factors, by and large, the focus remains on individual processes and outcomes. Recent scholarship in narrative psychology, specifically work on master narratives, has attempted to bridge this divide by bringing greater attention to the importance of the ideological setting in which individuals develop (Hammack, 2008; McAdams, 2006; McLean \& Syed, 2015). Whereas individuals hold personal ideologies, ideological settings are the broader societal-level beliefs and values that underlie a normative life in a given context.

In the US, normative ideology flows directly from the strongly held values of equal opportunity, meritocracy, and dispositionalism, embodied by the master narrative of the American 
Dream (Hochschild, 1996; Syed, 2016) ${ }^{1}$. This ideological setting minimizes the role of structural explanations for both success and struggle, locating them within individuals rather than their contexts. Moreover, the associated belief that anyone can succeed if they work hard enough implies that the social position variables (e.g., race/ethnicity) highlighted by García Coll et al. are not—and should not—be relevant, an ideology known as racial colorblindness. An important conceptual implication of ideological settings is that individuals within the setting will internalize and embody the normative ideology (McLean \& Syed, 2015). Of course, individuals are not passive recipients of normative ideology, but from a structural perspective it is imperative to understand the force the ideological setting can take on. Indeed, because the values and practices embedded within society at large are evident within our accumulated evidence and ongoing practices (Harris \& González, 2012), we argue that developmental psychology (and psychology more broadly) as a field reflects and reproduces racial colorblindness.

Racial colorblindness has been studied extensively as a psychological construct, largely as an individually-held attitude of the dominant, White, majority (see Rosenthal \& Levy, 2010 for a review). For example, Neville and colleagues (2000) define colorblind racial ideology as the denial, distortion, and minimization of race and racism in the US to maintain the racial status quo and White superiority. However, our use of the term racial colorblindness is more closely aligned with the sociological approach that goes beyond the individual level, describing its significance as an ideological setting (e.g., Bonilla-Silva, 2015). Racial colorblindness as an ideological setting follows from a racially-stratified society and "results in 'raceless' explanations for all sort of racerelated affairs” (Bonilla-Silva, 2015, p. 1364), such as school and residential segregation, educational advancement, and wealth accumulation. This tendency can be seen in a wide variety of research in developmental psychology, for example in racial comparative designs that often

\footnotetext{
${ }^{1}$ It should be obvious that ideological settings are culturally specific. For example, in many European countries, the ideology flows from the belief in national homogeneity vs. success through self-sufficiency (Gogolin, 2002).
} 
attribute developmental delays to presumed deficiencies of members of minority groups (Cauce et al., 1998), and in the use of race/ethnicity as an independent variable without also including assessments of the putative underlying process that would account for any observed differences between White and ethnic minority youth (e.g., socioeconomic differences, differential access to opportunity, see Gjerde, 2004; Helms, Jernigan, and Mascher, 2005). These issues have been discussed extensively in the literature, and we encourage interested readers to consult the preceding citations for more information. Our concern here is on the ideological setting in which research is conducted, and the corresponding broader values and beliefs that undergird our research practice.

\section{Expanding the Analytic Toolbox: Intersectionality as an Analytic Lens}

Scholarship on the interpretive framework of intersectionality has received increasing attention in recent years across numerous disciplines, including in psychology (Cole, 2009; Rosenthal, 2016). Intersectionality was developed and refined by Black feminists, women of color, and queer activists/scholars who challenged single identity politics in the U.S. civil rights movement, contributing the critical insight that systemic inequalities overlap in the lives of individuals (Crenshaw, 1991; Collins, 1989, Combahee River Collective, 1977; see Moradi \& Grzanka, 2017). As it emerged outside of psychology, intersectionality was originally (and continues to be) an interpretive framework for understanding societal processes and not individual psychological processes, per se (Crenshaw, 1991; see Syed \& Ajayi, in press). Using intersectionality to develop a systemic application of the integrative model involves an analysis of power dynamics and how multiple interlocking systems of oppression and affordances—beyond and within race and ethnicity—are associated with our research and institutional practices.

This perspective gained prominence in legal studies (Crenshaw, 1991), serving as an analytic lens for understanding representation and how broad social systems are conceptualized. Cole (2009) applied an intersectional approach to psychology, posing three questions pertaining to 
issues of research design and analysis (e.g., sample inclusion, interpretations). As Cole described, an analysis of power dynamics must lay at the core, rather than the periphery, of an inquiry into the development of both racial/ethnic minority and majority youth. Taking this approach merges the systems-focus of intersectionality within the individual empirical orientation of psychology. Indeed, research in developmental science has attempted to grapple with how individuals engage with systemic inequalities (e.g., Diemer \& Li, 2011). Although this work is noteworthy, it still relies on individual-level analyses. Our focus here is not on understanding structures for individual development, but understanding the structure surrounding the research being conducted.

In the present analysis, we use the analytic framework of intersectionality to understand racial colorblindness as an ideological setting in developmental science. Bringing an intersectional approach to colorblindness as an ideological setting brings attention to our core concept in this paper: how invisibilities are created and maintained in the field. Racial colorblindness as a concept implies invisibility, as it corresponds to a minimization of race as an important factor in the lives of minority and majority individuals; it seeks to make race invisible. At the same time, invisibility has been a strong contribution of psychological interpretations of intersectionality. Intersectional invisibility is a concept developed to bring attention to how our systems and dominant ways of thinking can lead to certain social identities and oppressions to be rendered invisible (PurdieVaughns \& Eibach, 2008; see also Ghavami \& Peplau, 2013). We build upon this definition by inserting racial colorblindness as the core system, or ideological setting, which creates and sustains the invisibilities of racial/ethnic minorities in developmental science.

Invisibilities can clearly be seen in the broader research base constituting developmental science (McLoyd, 2006; Quintana et al., 2006), which was the impetus for García Coll et al.’s (1996) integrative model in the first place. The invisibility of racial/ethnic minorities has been welldocumented through several content analyses of journals. In their review of articles published in 
APA and APS journals between 1993-1999, Nagayama Hall and Maramba (2001) found that only $6 \%$ of articles were focused on racial/ethnic minorities, and only $3 \%$ of articles in Developmental Psychology, arguably the leading APA journal focused on developmental science. Hartmann et al. (2013) conducted the same analysis for the period 2003-2009 and found little evidence for change, with $4 \%$ of all articles focused on racial/ethnic minorities, and 7\% of articles in Developmental Psychology. Focusing only on sample composition of three developmental journals between 20062010 (Developmental Psychology, Child Development, and Developmental Science), Nielsen, Haun, Kärtner, and Legare $(2017)^{2}$ found that $14 \%$ of articles included samples that were predominantly racial/ethnic minority, and a surprisingly high $28 \%$ did not mention the racial/ethnic composition at all. Taken together, these analyses document the invisibility of racial/ethnic minority samples in developmental research, and show no signs of major change over time. Thus, whereas the integrative model may have helped contribute to understanding more of the complexities of racial/ethnic minority development (see Quintana et al., 2006), it does not seem to have contributed to a major increase in the proportion of studies focusing on racial/ethnic minority youth. Importantly, the emphasis on invisibility should not be taken as an endorsement of racial/ethnic minority youth as passive, or as the seeds of a deficit-oriented research agenda. Individuals and researchers who are marginalized have agency, and respond to the issue of invisibilities in a variety of ways that are powerful and meaningful-they actively resist their invisibilities and fight to gain visibility (e.g., through the generation of special issues of journals, special topics meetings). We will highlight examples of such resistance, but also obstacles to resistance. In sum, adopting an intersectional analysis and considering the ideological setting in which the integrative model is situated facilitates an expansion of the model to the systemic level, bringing awareness to ongoing invisibilities in the field.

\footnotetext{
${ }^{2}$ These specific data were not detailed in the published report, but were provided by M. Nielsen via personal communication, September 13, 2017.
} 


\section{A Systemic View on Developmental Science}

What does a systemic view of developmental science mean? Most centrally, a systemic view implies that we consider not only our research findings in substantive terms but also broader issues pertaining to the research context itself. This includes how research is conducted, who is doing the research, the opportunities for conducting and disseminating research, and the incentive system that rewards research and productivity. We argue that understanding the context in which developmental research is carried out is intricately connected to what we "know" about developmental phenomena. Below we expand on our analytic framework, followed by an examination of major issues that serve as obstacles to pursuing a productive and inclusive developmental science, and a more inclusive psychological science more broadly.

Merging an intersectional perspective with the García Coll et al. (1996) integrative model yields new and important questions about how developmental science is conducted vis-á-vis diversity. In particular, the trio of factors in the model that had been under-represented in developmental science--social positions, social stratification mechanisms, and segregation--can be used to generate questions about the field as a whole, not just individual development. Consistent with our intersectional approach to understanding racial colorblindness as an ideological setting, our emphasis throughout the remainder of the paper is on the invisibilities created through our current research practice. Following the intersectional analytic device of posing questions to interrogate social systems (e.g., Cole, 2009), we generated three questions about invisibilities that correspond to the three non-shared factors of the integrative model: 1) social position: from whose vantage points is research conducted? 2) social stratification: what types of questions are valued? and 3) segregation: who gets left out from our work? Below we expand on each question and how it aligns with the corresponding factor of the integrative model. Collectively, the questions raise major issues concerning how we conduct our science, questions that all psychologists would do well to consider. 


\section{Social Position: From Whose Vantage Point is Research Conducted?}

Given the origins of empirical psychology in Western Europe and the US, it is hardly surprising that the mainstream perspective in the field represents beliefs, views, and interests valued by the dominant members of those cultures. Examinations of the samples included in research across psychology bears this out, overwhelmingly comprising White, American, middle-class ${ }^{3}$ samples (Arnett, 2003; Graham, 1992; Hall \& Maramba, 2001; Hartmann, et al., 2013; Henrich, Heine, \& Norenzayan, 2010; Nielsen et al., 2017). The result is a theoretical and empirical base that reflects a very small percentage of the world's population. In the integrative model, this invisibility of racial/ethnic minority populations is captured by the social position factor, which brings attention to social identity memberships (e.g., race, gender, social class) as well as attitudes and beliefs about the self and other. These social group memberships are the very ones that are minimized within a colorblind ideological setting. As we outline below, social position in a systemic context is manifest as invisibility with respect to both bodies and perspectives.

Invisibility of bodies. Invisibility of bodies pertains most directly to representation. At the most fundamental level, representation can be considered in terms of number of bodies; that is, a count of researchers from racial/ethnic minority groups with faculty appointments. On this metric, things look bleak. African Americans, Latinx, Asian Americans, and Native Americans continue to be underrepresented in the academy relative to their proportion in the US population; $22 \%$ of professors in the US are racial/ethnic minorities, whereas $42 \%$ of university students are racial/ethnic minorities (U.S. Department of Education, 2016). Representations are even smaller for women and faculty of color being promoted to full professorship (Stanley, 2006). In 2013, among full professors, 58\% were White males, 26\% were White females, $2 \%$ were Black males, $1 \%$ were Black females, 2\% were Latinx males, $1 \%$ were Latinx females, 7\% were Asian/Pacific Islander

\footnotetext{
${ }^{3}$ Samples have also likely comprised heterosexual, cisgendered, able-bodied, native born, linguistic majority, and religious majority participants, but researchers do not often collect this information.
} 
males, and 2\% were Asian/Pacific Islander females. Making up less than $1 \%$ each were professors who were American Indian/Alaska Native and of Two or more races (U.S. Department of Education, 2016). Furthermore, research on campus diversity rarely obtains information about faculty members' sexual orientation or gender identity, so representation of gender diverse and sexual minorities, and how they intersect with race/ethnicity, are unknown.

Specifically in the field of psychology, racial/ethnic minority faculty represented only $10 \%$ in 1999-2000 (APA, 2000) and 13\% in 2008-2009 (APA, 2010) of the total faculty responding from graduate departments of psychology in the United States. Data on awarded doctorates indicate greater prevalence and change over time: 18\% of Ph.D. recipients in psychology were racial/ethnic minorities in 1995, whereas this number had increased to 28\% by 2015 (National Science Foundation, 2017). In that year, the field of development psychology was slightly more diverse than psychology as a whole, with $34 \%$ of degree recipients being racial/ethnic minorities. Taken together with the faculty numbers, however, suggests that the increase in racial/ethnic minority Ph.D.s has not necessarily led to a proportionate increase in racial/ethnic minority faculty.

With the invisibility of racial/ethnic minority faculty also comes the invisibility of unique stressors encountered by these faculty (Vasquez et al., 2006). Since most research-intensive universities are predominantly White institutions, faculty of color often indicate alienation, overt and covert discrimination, and a devaluing of their research (e.g., Delgado Bernal, Elenes, Godinez, \& Villenas 2006). Individuals who belong to multiple marginalized groups (e.g., queer persons of color, women of color) are especially vulnerable to tokenism (double representation) and feeling burdened, with disproportionately more nurturing service responsibilities (e.g., mentoring students) and expected to serve on more cultural and diversity related committees than other faculty (Brayboy, 2003; Syed, 2017). They may also feel de-legitimized by colleagues and students when they are questioned about their credibility and competence (Pittman, 2010). These issues can often 
lead faculty who occupy these social positions, as noted in the integrative model, to feel socially isolated, marginalized, and invisible (Stanley, 2006). Within a colorblind ideological setting, issues of race, class, gender, and sexuality, which frame a scholar's experience within the academy, are continually overlooked, unchallenged, and unmonitored on a systemic level rendering faculties of color invisible (Stanley, 2006).

The issue of bodies of representation is complicated by the fact that attention to invisibilities in one dimension of diversity can potentially create different invisibilities. The current focus on racial/ethnic minority pan-ethnic group representation at the center of diversifying bodies in academia ignores other types of diversity (e.g., sexual identity, disability status, nationality, etc, and their intersections) that are needed in developmental science. For example, the current editorial boards of the Journal of Research on Adolescence, the flagship journal of the Society for Research on Adolescence, as well as Developmental Psychology, the flagship developmental journal of the American Psychological Association, are composed entirely of scholars from the US, despite the fact that they are diverse in other ways. Child Development is better in this regard, with $40 \%$ of the editorial board coming from outside the US. This is not to say that all editorial boards, departments, and so on, must perfectly represent all different intersections of subordinated identities, but rather how attention to some aspects of diversity can sometimes come at the expense of others.

Of course, representation goes beyond bodies. This argument has been used in support of the belief that increasing representation of individuals who care about diversity is a sufficient response, regardless of their race/ethnicity. We disagree with the practice of relying on this assertion to justify the chronic exclusion of individuals who belong to underrepresented groups. On the other hand, if diversity is measured and represented simply by a body count, this does not ensure diverse views when operating within an oppressive system, in which researchers are trained in the dominant way 
of thinking (Sue, 1999). In other words, being a racial/ethnic minority individual does not automatically ensure attention to minority issues.

Invisibility of perspectives. As articulated in the integrative model, social position includes not only social identity group memberships but also the attitudes and beliefs associated with those groups (García Coll et al., 1996). Psychology is dominated by a particular perspective or vantage point that not only guides the field, but also works to maintain the invisibility of marginalized racial/ethnic perspectives. This dominant vantage point is rooted in colorblind ideology, at best in its passive form of simply ignoring racial/ethnic minority voices and at worst in actively excluding them (Syed, 2017). Accordingly, the dominant vantage point fails to capture interlocking systems of privilege and oppression, further promoting intersecting invisibilities.

One way to see this process in action is to examine mainstream advancements in studying culture and diversity. For instance, Markus and Kitayama’s (1991) articulation of independent and interdependent self-construals has been a hugely influential model (cited over 18,000 times), seeking to highlight the limitations of the universalist thinking of psychology, and social psychology in particular. But this highly over-simplified dichotomous way of thinking about selves was easily accommodated by a universalist perspective; it did not require any change to the thinking about psychological processes among those using samples from the United States and Europe, save for perhaps limits on the perceived generalizability of the findings (see also Shweder, 2000, on why cross-cultural psychology is more widely accepted than cultural psychology). Moreover, although the article brought attention to potential cultural factors, it said little about racial/ethnic diversity.

Similarly, Henrich, Heine, and Norenzayan's (2010) article on the over-reliance of WEIRD samples (Western, Educated, Industrialized, Rich, Democratic) makes essentially no reference to race/ethnicity as a potential limiting factor of past study designs. The article has made a huge impact, garnering over 3000 citations in over just seven years, and yet largely works in the same 
way as Markus and Kitayama (1991) in that it specifies boundary conditions for generalizability more than bringing attention to persistent invisibilities. Thus, even when there is an opening to new ways of thinking about diversity in psychological processes, such an opening can paradoxically serve to reinforce the existing vantage points and maintain the invisibility of racial/ethnic minorities. Furthermore, citation counts suggest that psychological researchers are much more willing to accept and incorporate limitations of their fields with respect to cultural/national representation than they are with respect to racial/ethnic representation. For example, Graham’s (1992) article, “Most of the subjects were White and middle class: Trends in published research on African Americans in selected APA journals, 1970-1989” published in American Psychologist around the same time as Markus and Kitayama (1991) and well before Henrich et al. (2010) has only been cited 620 times, compared with 18,588 and 3,657, respectively. These data speak to the field of psychology at large, and not developmental psychology specifically, but they say something about the broader context of the field, and there is little reason to believe that developmentalists are exempt from this context.

The historic and ongoing exclusion of research with racial/ethnic minority populations means that there are substantial gaps in our knowledge of core developmental issues. These gaps include understanding how existing research on psychological processes conducted with White samples applies to racial/ethnic minority populations. For example, research on the timing and meaning of family conflict among White parents and adolescents has long assumed that early adolescence is when we see the highest level of conflict (Laursen, Coy, \& Collins, 1998), followed by decreases into young adulthood (Whiteman, McHale, \& Crouter, 2011), and that parentadolescent conflict during adolescence is developmentally appropriate and normative. In contrast, for Chinese American adolescents parent-adolescent conflict may peak during mid adolescence, not early adolescence (Juang, Hou, Douglass Bayless, \& Kim, 2017) and rather than the usual portrayal 
of parent-adolescent conflict as damaging to relationships among immigrant families, some family conflict during adolescence is also developmentally appropriate (see Juang, Syed, Cookston, Wang, \& Kim, 2011). Thus, in this case, inclusion of diverse populations in our research challenges our views of what is "normative" for certain populations.

The gaps in developmental knowledge also consist of constructs and processes that were under-examined or overlooked entirely due to the focus on racial/ethnic majority populations. For example, although the construct of socialization has a long history in developmental psychology (Grusec, 2011), only relatively recently have researchers began to study cultural socialization, or how parents, peers, and other agents transmit messages regarding ethnicity and race to their children (and vice versa; Hughes et al., 2006). This is a major oversight as Garcia Coll et al.'s (1996) model shows that race/ethnicity and related experiences such as segregation, racism, and discrimination, are central to racial/ethnic minority child development. As such, ignoring how parenting develops and operates in relation to these issues misses a key piece of parent-child relationships.

Despite the lack of mainstream psychological attention, there are alternative views that have worked to expose the invisibility of racial/ethnic minority issues just as the integrative model intended. For example, ethnic minority psychology (or multicultural psychology; Hall, Yip, \& Zárate, 2016), is a field that is dedicated to understanding culturally-relevant processes among racial/ethnic minorities, and is thereby a clear rejection of the colorblind ideology. Empirical studies examine a wide range of coping strategies and resiliency developed by youth of color and their families to navigate, negotiate, and resist discrimination (Hughes et al., 2006; Quintana et al., 2006; Umaña-Taylor et al., 2014), as well as how they engage with the broader society in terms of sociopolitical development, critical consciousness, and activism (e.g., Diemer \& Li, 2011).

But, as noted, this research largely operates outside of the mainstream of developmental psychology. Hartmann et al.’s (2013; Table 2) content analysis of journal articles published in 
2003-2009 clearly indicated that most research focused on racial/ethnic minorities was published in either medical journals or in specialty journals dedicated to research on those populations (e.g., Cultural Diversity and Ethnic Minority Psychology, Journal of Black Psychology, Hispanic Journal of Behavioral Sciences). One striking counter-example is Journal of Youth and Adolescence, which has a relatively high number of articles on racial/ethnic minorities both in the absolute sense $(N=$ 144) and relative to the total number of publications (28\%). These numbers are much higher than for Developmental Psychology ( $N=52$ and 7\%). Importantly, some caution is warranted when interpreting journal content within a relatively circumscribed timeline. McLoyd (2006) carefully detailed the history of the editorial board of Child Development, describing how the content of the journal pertaining to racial/ethnic minorities changed along with editorial transitions. Indeed, in 2014 the journal instituted a "sociocultural policy," meaning that authors are now required to provide detailed information about samples when theoretically relevant. As this policy mandates reporting rather than inclusion in the study design, it is difficult to know what impact, if any, it will have. Nevertheless, these types of institutional changes are precisely what are needed to initiate changes to current practice.

\section{Social Stratification Mechanisms: What Types Of Questions Are Valued?}

In the integrative model, social stratification mechanisms serve as the central mediator between social position and contexts of racial/ethnic minority youth development. García Coll and colleagues (1996) specify these mechanisms as racism, discrimination, and prejudice--clearly all variations of the theme of differential access to power within a racially-stratified society. This factor of social stratification is already conceptualized at the systemic level, facilitating applications to the field of developmental science. We define social stratification in the research context as the types of research questions and topics that are valued, as those questions that are more culturally valued are also those that are more likely to be favorably reviewed for journals and grants, two major 
indicators of success and prestige (see Sternberg, 2016 for evidence of these values). Our intersectionality-inspired analytic approach leads us to focus on issues of power and social structures in terms of how "value" is conceptualized. Below we provide examples of how these valued questions (e.g., agency-based and biological models) are derived from the colorblind ideological setting, lead to further invisibilities of racial/ethnic minorities, and how differences in values have led to both gaps in knowledge and more long-term delays in cumulative knowledge.

The individual-focused tendency that flows from the racial colorblind ideological setting is reflected in the types of research that gains broad popular national and international recognition. Two prominent examples-- one from developmental psychology and one from personality psychology--are both agency-based models that have implications for educational policy and practice. Research on the benefits of developing a growth mindset for academic success focuses on individual cognitions and interactions between children and teachers/parents (Dweck, 2006). However, interventions aimed at fostering growth mindsets do nothing to change the structure of the educational system, so do not engage with critical issues associated with educational disparities, such as ability grouping ("tracking”), disciplinary norms, and funding. Similarly, grit, which is the passion and perseverance linked to academic success (Duckworth, Peterson, Matthews, \& Kelly, 2007), is conceptualized as a personality trait (and is indistinguishable from conscientiousness; Credé, Tynan, \& Harms, 2016). Thus, interventions seeking to foster grit are dispositionally based rather than systemic. Grit, too, is interesting in that it so nicely aligns with the "success through hard-work" component of the American Dream master narrative. This point can be generalized to the broader valuing of the concept of agency throughout psychology, and the general failure to contextualize agency within overlapping systems of oppression and privilege (see Whaley, 2009, for a similar critique of stereotype threat research). Thus, when considering the ideological setting 
in which the research was produced and disseminated, it is little surprise that growth mindset, grit, and other agency-based concepts have taken hold.

The current research zeitgeist in developmental psychology (and psychology more broadly; Schwartz, Lilienfeld, Meca, \& Sauvigné, 2015) on biological processes is a contemporary example of the ongoing barriers to the advancement of racial/ethnic minority psychology. Schwartz et al. (2015) documented shifts in federal funding priorities, research design choices, and hiring practices towards biological perspectives on psychological issues. However, the legacy of scientific racism has led to skepticism about biological research with racial/ethnic minority groups (Rowley \& Camacho, 2015). Identifying genetic markers or neural processes associated with psychological processes that differentiate minority and majority groups, especially in terms of race, runs the risk of such differences being interpreted as natural, innate, and unchangeable (Gould \& Heine, 2012). Accordingly, both researchers and potential participants may be hesitant to engage in such research. Because this work is highly valued in the field, in terms of available jobs and grants (Schwartz et al., 2015), not engaging in this work places racial/ethnic minorities at a disadvantage relative to their majority peers. Of course, this is not the case across the board-there has been an emergence of research examining cultural and biological levels of analysis (see volume by Causadias, Telzer, \& Gonzalez, in press), but nevertheless many concerns about this approach remain.

The preference for certain types of questions over others also leads to gaps in our knowledge, even in areas of research most relevant to minority groups such as the study of racial/ethnic discrimination. It was not until the end of World War II when there was a more conscious recognition and discussion of racial/ethnic biases and discrimination, which led researchers to shift from research questions supporting scientific racism to asking why, how, and when individuals were racist at the individual level (Richards, 1997). This led to a cumulative body of knowledge of how individual differences (e.g., authoritarian personality), cognitive, affective, 
and group interactions and processes of mostly Whites formed and maintained racist views (Fiske, 1998). During this time, there was little theoretical and empirical attention to the history of race and racism, roles of White power and privilege, historical and institutional structures of interlocking forms of oppression, and more importantly, perspectives and experiences of actual people of color that were marginalized as a consequence of racism.

Starting from the 1970s, along with the U.S. civil rights movement, psychologists began to focus on the perspective and agency of racial/ethnic minority groups in how they make meaning, struggle, and cope with racism (Winston, 2004). Related theories and empirically validated measures of racial/ethnic discrimination from a minority perspective continually flourish today with more specific experiences grounded in the history and identity of the marginalized groups (e.g., Gendered Racial Microaggressions Scale for Black women; Lewis \& Neville, 2015). Where once there were few validated self-report measures of perceived racism that primarily focused on racialized experiences of African Americans, a recent review identified 24 validated instruments grounded in diverse theoretical and racial/ethnic populations (Yoo \& Pituc, 2013).

Still, there are many marginalized groups that are understudied. For instance, a great deal of the pioneering research on constructs relevant to racial/ethnic minority populations was conducted with African Americans, with less attention to other minority groups (see Hughes et al., 2006). Although there are certainly some shared experiences among racial/ethnic minority groups due to being a minority in a racially-stratified society, there are important distinctions and racial trajectories of groups that normalize and reinforce White racism (e.g., stereotypes of Asian Americans as the model minority in contrast to African Americans as lazy and dangerous; Omi \& Winant, 1995). Empirical examination of these other groups (e.g., Asian American, Pacific Islander, Latinx, Indigenous) grounded in their unique racialized history and contexts have far less representation. The value of such perspectives can be seen in the response to Lilienfeld's (2017) 
critique of microaggression research. In offering a detailed critique of a field he had no prior involvement with, he unintentionally illustrated the potential consequences of not being familiar with the history or context of a construct (Kraus \& Park, 2017). Moreover, he either downplayed or dismissed altogether the voiced experiences of racial/ethnic minorities themselves who have been subject to such slights.

Research on racial/ethnic identity development illustrates how a delayed focus on minorityrelated constructs leads to a concomitant delay in cumulative development knowledge. The identity status model, a widely used model of identity in developmental psychology focusing on the domains of occupation, religion, politics, friendships, etc., was developed in the 1960s (Marcia, 1966) and used extensively across the 1970s and 80s (see van Hoof, 1999). It was not until the 1990s that researchers began to examine ethnicity as a domain within the model in earnest (Phinney, 1990). Much of the next decade and a half was spent conducting basic descriptive and correlational research on the model, and there were almost no longitudinal studies until the mid2000s (French et al., 2006; Pahl \& Way, 2006). Comparable research for the other identity status domains was conducted nearly 30 years prior.

Beyond the importance of the lack of cumulative developmental knowledge, this delayed start for racial/ethnic identity development research made it difficult for interested researchers to disseminate their work in high-impact publication outlets. The journals considered prestigious in the field place a strong emphasis on unearthing causal processes, but it is impossible to speak to causality among constructs when the constructs themselves are not properly understood. Thus, from a systemic perspective, the historical lack of inclusion of minority-relevant constructs leads to disparities even when they begin to be included, given that we operate in a system that rewards dissemination in particular journals (see Syed, 2017).

\section{Segregation: Who Gets Left Out?}


Like social stratification, segregation serves as a mediator between social position and youth contexts in the integrative model. Segregation is not only residential, but economic, social, and psychological (García Coll et al., 1996). As noted in the previous section, stratification concerning what is scientifically valued leads to segregation (exclusion) of topics and populations of study. The original integrative model was intended to address development of "minority" children broadly construed, but it has subsequently been used largely to understand the development of racial/ethnic minority children. One of the values of an intersectional analytic lens is that it highlights how bringing attention to invisibilities in one aspect of diversity (e.g., race/ethnicity) can lead to lack of attention to other aspects of diversity. The issue of invisibilities in the developmental sciences is especially pronounced among individuals who belong to multiple marginalized groups, including those who experience multiple and overlapping systemic forces of oppression (e.g., racism and heterosexism). This is even the case within dimensions of diversity. As noted previously, the accumulated psychological knowledge is uneven across different racial/ethnic minority groups, with much more research being conducted with African Americans than with other groups. For example, Filipino Americans are the third largest group of Asian Americans, with the longest history in the US, and yet there are still relatively few studies focusing on them (see Nadal, 2011). Accordingly, there is a need to expand the "invisibilities" researchers explore. In this next section, we highlight three intersections to illustrate the point: sexual minority youth of color, immigrant youth with disabilities, and racial/ethnic minorities in an international context.

Sexual minority youth of color. Sexual minority youth of color have been chronically excluded from research with youth in general, but also research with sexual minority youth. Using the broad criteria of locating any published studies since 1990 focused on health and well-being that included sexual minority youth of color in its sample, Toomey et al. (2016) were able to identify 125 reports but found that a very small proportion of these studies examined some form of 
intersections of racism and heterosexism by exploring, for example, the intersections of racial/ethnic and sexual minority identities. Moreover, studies tended to adopt a deficit framing versus one that considers cultural strengths and normative development.

There has been limited attention paid to the development of sexual minority youth in the developmental sciences, with research on gender-related traits, concepts, and attitudes often examined from the perspective of sexual-dominant youth (Zosuls et al., 2009). During a 2017 peer research pre-conference meeting related to gender and LGBTI youth preceding the meeting of the Society for Research in Child Development, scholars noted that we, in fact, are not even sure how to ask developmentally appropriate and gender-inclusive questions about sexuality to children and youth in the general population. The forces of homophobia and heterosexism promote the invisibilities faced by sexual minority children and youth in schools, as school principals and district-IRB's may be reluctant to allow questions related to sexuality in surveys of children and youth (although there are exceptions, e.g., Poteat et al., 2016). These challenges only serve to further marginalize individuals who experience oppression related to being a sexual minority or gender non-conforming.

Immigrant youth with disabilities. Disabilities can encompass sensory, cognitive, physical, or psychological impairments. Immigrant children who have a disability experience an additional layer of challenge for adjustment if teachers and schools are unfamiliar with issues of immigration (Birman \& Tran, 2015) and lack appropriate support and services, all of which may lead to greater stigmatization and marginalization (Suárez Orozco, Suárez Orozco, \& Todorova, 2010). Including an intersectional perspective avoids painting an overly simplistic view of their experiences, but few studies have focused on immigrant children with disabilities.

From a disability critical race theory perspective, the term "racial colorblindness" is viewed as problematic as it frames colorblindness as a disability, as a weakness, a limitation which then 
confounds dismissing race with a deficit-oriented portrayal of people with disabilities (Annamma, Jackson, \& Morrison, 2016). Racial colorblindness falsely equates blindness (not seeing) with ignorance. A suggested alternate term is “color evasiveness” to better capture a racial ideology using a term that does not contribute to positioning people with disabilities as lacking something or being deficient (Frankenburg, 1993). This issue of terminology highlights the need to always assess assumptions and bias that may be embedded in our scholarship, and how even when focused on addressing one form of oppression we inadvertently engage in another.

Racial/ethnic minorities in an international context. There is a great need for understanding the experiences and development of racial/ethnic minorities within an international context. Psychological research on racial/ethnic minorities is dominated by U.S.-centric models of minority developmental processes. Although there is research on racial/ethnic minority development in countries such as The Netherlands (Verkuyten \& Yildiz, 2007), Germany (Frankenburg, Kupper, Wagner, \& Bongard, 2013), and South Africa (Ferguson \& Adams, 2016), the research base is still heavily skewed by research in the US. Expanding the national contexts will bring greater attention to some overlooked populations within developmental research. The United States' population constitutes less than $5 \%$ of the world's population, clearly signaling that the accumulated research does not represent human diversity (Arnett, 2008), and also that such a strong focus on the US and its peculiarities may lead us to miss important aspects of development (see also the limitations of WEIRD samples, Henrich et al., 2010). For example, unlike the US, in Africa, Europe, and parts of Asia most children are multilingual; yet, most of our understanding of language development, having been conducted in the US, is not focused on studies of multilingual children.

A major challenge of using U.S. developed constructs to understand racial/ethnic minority psychology in countries other than the US is that basic systems and constructs may not transfer. For 
example, the categories for racial/ethnic groups used in the US are not used in countries such as Germany or Sweden, which rely more heavily on an immigrant/non-immigrant dichotomy (Gyberg, Frisén, Syed, Wängqvist, \& Svensson, 2017), or countries such as South Africa, which has a classification system that reflects its long history with colonialism (Ferguson \& Adams, 2016). Nevertheless, basic constructs developed in the US, including racial/ethnic identity, cultural socialization, and perceived discrimination can be fruitfully explored outside of the United States.

\section{The Path Forward}

In the preceding sections, we highlighted various factors that contribute to intersectional invisibilities in the developmental sciences and beyond. We conclude our analysis by expanding on the preceding to consider potential paths of change. To do so, we highlight avenues for change that align with each of the three questions motivated by the intersectional analytic lens.

\section{Expanding Social Positions: Diversifying the Faculty and Broadening the Vantage Points}

We need to have both new ways of thinking represented in our science and greater diversity of the bodies doing the science. One without the other will not do. Importantly, universities must make diversity and issues of representation central to discussions of hiring at every step of the process, including how diversity impacts and shapes what positions need to be filled, who chairs and sits on the search committee, and how advertisements are worded. For instance, a critical means through which developmental programs, and universities alike, can promote diversity in science is to engage in the practice of promoting diversity cluster hires, which are considered best practice (Sgoutas-Emch, Baird, Myers, Camacho, \& Lord, 2016). This practice is especially important in promoting a sense of community for faculty doing research in this area who often find themselves alone and marginalized within their own programs by virtue of having a line of research that makes diversity central to scholarship (Stanley, 2006). Promoting a sense of community among these faculty is an important tool in promoting not only recruitment but also retention. More retention 
efforts of minority faculty are needed at the institutional level. In addition to cluster hiring, faculty mentoring programs, diversity funding initiatives, and other programs should be evaluated to examine not only what minority faculty need to survive, but also thrive. Furthermore, emphasizing the need for more recruitment, retention, and achievement of faculty of color does not eliminate the commitment, responsibility, and role of White faculty needed to help promote more diverse and inclusive environment in psychology.

At the center of diversity and representation efforts, one must also address the need for equity and social justice. It is important to remember that social inequities are not a simple byproduct of "lack of inclusion." Rather, inequities are a consequence of the power conferred to the dominant group—both historically and contemporarily—-that have shaped the different lived experiences between "majorities” and “minorities.” Therefore, it is not only about the diverse representation of faculty and research, but also addressing the inequity within the system, such as what type of research and teaching is valued, disproportionate service load, and who gets promotion and tenure. It is important for the uninitiated to be aware that there are resources available to help guide such efforts. Presumed Incompetent, is an extensive compilation of essays and analyses from women of color faculty writing about their experiences in academia across the US. The volume includes a detailed list of recommendations for administrators, faculty, and allies to promote university climates that will eliminate tokenism and provide a context enabling diverse women of color to succeed (Muhs, Niemann, Gonzales, \& Harris, 2012).

In addition to increasing the representation of diverse bodies, the advancement of an inclusive developmental science requires making space for new perspectives that do not neatly fit with existing models. One approach is to direct resources from existing structures that have not historically supported alternative views. For example, organizations and societies can promote systemic change by encouraging the formation of study groups that bring together young scientists 
advocating change in the field in coalition with senior scholars who are open to this work. The Society for Research on Adolescence, for example, funded the Intersectionality in the Developmental Sciences Study Group, which aims to infuse an intersectionality-inspired perspective in theory, methods and practice within developmental psychology. This approach might be uncomfortable for some, as it necessarily requires re-direction of resources away from projects rooted in traditional vantage points. However, recognizing that this type of investment is beneficial for the field as a whole would go a long way to reducing such discomfort.

A complementary approach to one that re-directs existing resources is to make room for different types of research than is typical in psychology. Developmental research has long been closely linked with policies and practices out in the world, but by and large in terms of how to translate research into policy and practice. Within this larger endeavor of linking systems-level processes (e.g., laws and policies) with individual level processes, one critical omission in the developmental literature is a consideration of the developmental and psychological implications of a burgeoning area of research in legal studies on legal consciousness. In a recent study, Santos and colleagues (in press) attempted to bridge legal consciousness perspectives with a developmental framework. By asking youth how aware they were of Arizona's controversial immigration law SB1070, a perspective from youth on laws that we seldom, if ever, consider capturing in developmental science, they were able to show longitudinally that greater awareness of SB1070 predicted later drops in performance at school among Latino males. Thus, rather than viewing the research-to-policy link in linear terms, this type of research reflects the deep embeddedness of the two in the lives of youth of color.

\section{Breaking Down Social Stratification: Valuing a Broader Array of Questions}

Valuing a broader array of research questions in the field is no easy task, as it requires a reexamination of deeply held convictions about the nature of our science. First, doing so will require 
rejecting the idea that unearthing causation is the gold standard of our work. Rather, identifying potential causal mechanisms for psychological phenomena should be viewed as one of many valuable research activities. Basic observational and descriptive research, which is the bedrock of a solid science, ought to be just as worthy of grant funding and publication in flagship journals. Given the historical exclusion of research with racial/ethnic minorities, such a perspective is all but necessary to move toward a more inclusive and equitable science (Syed, 2017).

On a related note, the valuing of quantitative over qualitative methods is another tension in our field that limits our ability to diversify what questions we ask and value. For example, the chronic preference of quantitative methods and the viewing of these approaches as inherently incompatible limits our understanding that the wording of our measures, our models, and theories are inextricably linked to lived experiences and narratives. The siloing of quantitative and qualitative methods limits researchers’ abilities to ask important and relevant questions in their work. For example, there is a rich tradition in participatory methods to value the perspective and voices of who gets studied. Although we encourage thoughtful engagement with this practice, we see potential in having conversations with participants at the onset of a study, whether quantitative or qualitative. For example, members a community being studied can provide invaluable insight on the ways in which measures, goals, and conceptualizations of phenomena misses the mark (or not) in relation to their lived experiences. Valuing these voices does not mean giving up our training and skills. Rather, it shows that we value the perspective of individuals embedded within the communities we study (Rosenthal, 2016).

\section{Reducing Segregation: Building Coalitions to Promote Inclusiveness}

As we move towards a more inclusive science, it is also critical to continuously ask the question of who is being left out of those advances. Again, this process is not meant to be a full representational “check-box” of all configurations of subordinated social groups. It is instructive to 
recall that Crenshaw’s (1991) writing on intersectionality was a critique of identity politics and called for a recognition that identity groups themselves are coalitions (e.g., the collective identity "LGB” is composed of coalitions of women, men, people of various racial/ethnic backgrounds, social classes, etc.). The challenge of intersectionality theory to scholar-activists was to focus on systems (i.e., heterosexism, racism, sexism) rather than on identities/identity groups, and to build coalitions across single identity categories to challenge these systems (Moradi \& Grzanka, 2017). Thus, efforts aimed at building and maintaining coalitions (e.g., cluster hires) are likely to have the greater impact on reforming the current system.

\section{Conclusions}

The purpose of this paper was to bring a systemic perspective to developmental science through a discussion of current practices in the field. Merging an intersectional analysis with García Coll et al.’s (1996) integrative model facilitated a focus on how developmental psychology, and psychology more broadly, creates and sustains the invisibility of racial/ethnic minorities. The three questions discussed in the paper: From whose vantage point is research conducted? What types of questions are valued? And who gets left out? highlight the complexities of the issues. Of course, these are not the only three questions that can—or should—be asked. But as our society and field continue to diversify, questions must be asked. Only by asking such questions and bringing greater awareness to the oppressive context of current research practices can we possibly begin to generate solutions that will benefit science for all. 


\section{References}

American Psychological Association. (2000). Data on race/ethnicity. Retrieved September 16, 2003, from http://research.apa.org/racefig7.html

American Psychological Association. (2010). 2008- 2009 Faculty in U.S. and Canadian Graduate Departments of Psychology. Retrieved September 10, 2017, from http://www.apa.org/workforce/publications/10-grad-study/index.aspx

Annamma, S.A., Jackson, D.D., \& Morrison, D. (2016). Conceptualizing color-evasiveness: Using dis/ability critical race theory to expand a color-blind ideology in education and society. Race, Ethnicity and Education, 2 - 16.

Arnett, J. J. (2008). The Neglected 95\%: Why American Psychology Needs to Become Less American. American Psychologist, 63(7), 602-614.

Balsam, K. F., Molina, Y., Beadnell, B., Simoni, J., \& Walters, K. (2011). Measuring multiple minority stress: the LGBT People of Color Microaggressions Scale. Cultural Diversity and Ethnic Minority Psychology, 17(2), 163

Birman, D., \& Tran, N. (2015). The academic engagement of newly arriving Somali Bantu students in a U.S. elementary school. Washington DC: Migration Policy Institute.

Bonilla-Silva, E. (2015). The structure of racism in color-blind,“post-racial” America. American Behavioral Scientist, 59(11), 1358-1376.

Brayboy, B. (2003). The implementation of diversity in predominantly white colleges and universities. Journal of Black Studies, 34(1), 72-86.

Bronfenbrenner, U. (1979). The ecology of human development: Experiments by nature and design. Cambridge, MA: Harvard University Press. 
Cauce, A.M., Coronado, N., \& Watson, J. (1998). Conceptual, methodological, and statistical issues in culturally competent research. In M. Hernandez \& R. Mareasa (Eds.), Promoting cultural competence in children’s mental health services. Baltimore: Paul Brooks Publishing.

Cole, E. R. (2009). Intersectionality and research in psychology. American Psychologist, 64(3), 170-180.

Collins, P. H. (1989). The social construction of Black feminist thought. Signs: Journal of Women in Culture and Society, 14, 745-773.

Combahee River Collective. (1983). The Combahee River Collective statement. In B. Smith (Ed.), Homegirls: A Black feminist anthology (pp. 264-274). New York, NY: Kitchen Table, Women of Color Press. (Original work published 1977)

Crenshaw, K. (1991). Mapping the margins: Intersectionality, identity politics, and violence against women of color. Stanford Law Review, 43(6), 1241-1299.

Credé, M., Tynan, M. C., Harms, P.D. (2016). Much ado about grit: A meta-analytic synthesis of the grit literature. Journal of Personality and Social Psychology.

Delgado Bernal, D., Elenes, C.A., Godinez, F., \& Villenas, S. (2006). Chicana/Latina Education in Everyday Life: Feminista Perspectives on Pedagogy and Epistemology. Albany: State University of New York Press.

Diemer, M. A., \& Li, C. H. (2011). Critical consciousness development and political participation among marginalized youth. Child Development, 82(6), 1815-1833.

Duckworth, A. L., Peterson, C., Matthews, M. D., \& Kelly, D. R. (2007). Grit: Perseverance and passion for long-term goals. Journal of Personality and Social Psychology, 92(6), 10871101.

Dweck, C. S. (2006). Mindset: The new psychology of success. New York: Random House. 
Ferguson, G. M., \& Adams, B. G. (2016). Americanization in the rainbow nation: Remote acculturation and psychological well-being of South African emerging adults. Emerging Adulthood, 4(2), 104-118.

Fiske, S. T. (1998). Stereotyping, prejudice, and discrimination. In D. T. Gilbert, S. T. Fiske, \& G. Lindzey (Eds.), The handbook of social psychology, Vols. 1 and 2 (4th ed.) (pp. 357-411). New York: McGraw-Hill.

French, S. E., Seidman, E., Allen, L., \& Aber, J. L. (2006). The development of ethnic identity during adolescence. Developmental Psychology, 42, 1-10.

García Coll, C., Crnic, K., Lamberty, G., Wasik, B. H., Jenkins, R., Garcia, H. V., \& McAdoo, H. P. (1996). An integrative model for the study of developmental competencies in minority children. Child Development, 67(5), 1891-1914.

Ghavami, N., \& Peplau, L. A. (2013). An intersectional analysis of gender and ethnic stereotypes: Testing three hypotheses. Psychology of Women Quarterly, 37(1), 113-127.

Gjerde, P. F. (2004). Culture, power, and experience: Toward a person-centered cultural psychology. Human Development, 47(3), 138-157.

Gogolin, I. (2002). Linguistic and cultural diversity in Europe: A challenge for educational research and practice. European Educational Research Journal, 1(1), 123-138.

Gould W.A. \& Heine S.J. (2012) Implicit essentialism: Genetic concepts are implicitly associated with fate concepts. PLoS ONE 7(6): e38176.

Graham, S. (1992). 'Most of the subjects were white and middle class': trends in published research on African Americans in selected APA journals, 1970-1989. American Psychologist, 47, 629-639.

Grusec, J. E. (2011). Socialization processes in the family: Social and emotional development. Annual Review of Psychology, 62, 243-269. 
Gyberg, F., Frisén, A., Syed, M., Wängqvist, M., \& Svensson, Y. (2017). Another kind of Swede: Swedish youth’s ethnic identity narratives. Emerging Adulthood.

Hall, G. C. N., Yip, T., \& Zárate, M. A. (2016). On becoming multicultural in a monocultural research world: A conceptual approach to studying ethnocultural diversity. American Psychologist, 71(1), 40-51.

Hammack, P. L. (2008). Narrative and the cultural psychology of identity. Personality and Social Psychology Review, 12(3), 222-247.

Hartmann, W. E., Kim, E. S., Kim, J. J., Nguyen, T. U., Wendt, D. C., Nagata, D. K., \& Gone, J. P. (2013). In search of cultural diversity, revisited: Recent publication trends in cross-cultural and ethnic minority psychology. Review of General Psychology, 17(3), 243-254.

Helms, J. E., Jernigan, M., \& Mascher, J. (2005). The meaning of race in psychology and how to change it: a methodological perspective. American Psychologist, 60(1), 27.

Henrich, J., Heine, S.J., \& Norenzayan, A. (2010). The weirdest people in the world? Behavioral and Brain Sciences, 33, 61-83.

Hochschild, J. L. (1996). Facing up to the American dream: Race, class, and the soul of the nation. Princeton University Press.

Hughes, D., Rodriquez, J., Smith, E. P., Johnson, D. J., Stevenson, H. C., Spicer, P. (2006). Parents’ ethnic-racial socialization practices: A review of research and directions for future study. Developmental Psychology, 42, 5, 747-770.

Juang, L., Hou, Y., Douglass Bayless, S., \& Kim, S.Y. (under review). Time varying effects of family conflict and adolescent adjustment among Chinese American families.

Juang, L., Syed, M., Cookston, J., \& Wang, Y., \& Kim, S.-Y. (2012). Everyday and acculturationbased family conflict among Chinese American parents and adolescents. New Directions for Child and Adolescent Development. San Francisco: Jossey-Bass. 
Kraus, M. W., \& Park, J. W. (2017, March 20). Microaggressions as part of the historical context of stigma and prejudice. Retrieved from osf.io/preprints/psyarxiv/622ke

Laursen B., Coy K., \& Collins W. A. (1998) Reconsidering changes in parent-child conflict across adolescence: a meta-analysis. Child Development, 69, 817-832.

Lewis, J. A., \& Neville, H. A. (2015). Construction and initial validation of the Gendered Racial Microaggressions Scale for Black women. Journal of Counseling Psychology, 62(2), 289

Lilienfeld, S. O. (2017). Microaggressions: Strong claims, inadequate evidence. Perspectives on Psychological Science, 12 (1), 138-169.

Marcia, J. E. (1966). Development and validation of ego-identity status. Journal of Personality and Social Psychology, 3(5), 551-558.

Markus, H. R., \& Kitayama, S. (1991). Culture and the self: Implications for cognition, emotion, and motivation. Psychological Review, 98(2), 224-253.

McAdams, D. P. (2006). The redemptive self: Stories Americans live by-revised and expanded edition. Oxford University Press.

McLean, K. C., \& Syed, M. (2015). Personal, master, and alternative narratives: An integrative framework for understanding identity development in context. Human Development, 58, 318-349.

McLoyd, V. C. (2006). The role of African American scholars in research on African American children: Historical perspectives and personal reflections. Monographs of the Society for Research in Child Development, 71(1), 121-144.

Moradi, B., \& Grzanka, P. R. (2017). Using intersectionality responsibly: Toward critical epistemology, structural analysis, and social justice activism. Journal of Counseling Psychology, 64, 500-513. 
Muhs, G. G. \& Niemann, Y. F. \& González, C. G. \& Harris, A. P. (2012). Presumed incompetent: The intersections of race and class for women in academia. Logan: Utah State University Press.

Nadal, K. L. (2011). Filipino American psychology: A handbook of theory, research, and clinical practice. John Wiley \& Sons.

Nagayama Hall, G. C., \& Maramba, G. G. (2001). In search of cultural diversity: Recent literature in cross-cultural and ethnic minority psychology. Cultural Diversity And Ethnic Minority Psychology, 7(1), 12-26.

Neville, H. A., Lilly, R. L., Duran, G., Lee, R. M., \& Browne, L. (2000). Construction and initial validation of the Color-Blind Racial Attitudes Scale (CoBRAS). Journal of Counseling Psychology, 47(1), 59.

Nielsen, M., Haun, D., Kärtner, J., \& Legare, C. H. (2017). The persistent sampling bias in developmental psychology: A call to action. Journal Of Experimental Child Psychology, 16231-38.

Omi, M. \& Winant, H., (1994). Racial formation in the United States. From the 1960s to the 1990s.

Pahl, K. \& Way, N. (2006). Longitudinal trajectories of ethnic identity among urban black and Latino adolescents. Child Development, 77(5), 1403-1415.

Pittman, C. T. (2010). Race and gender oppression in the classroom: The experiences of women faculty of color with white male students. Teaching Sociology, 38(3), 183-196.

Poteat, V. P., Scheer, J. R., \& Chong, E. S. (2016). Sexual orientation-based disparities in school and juvenile justice discipline. Journal of Educational Psychology, 108(2), 229-241.

Purdie-Vaughns, V. \& Eibach, R.P. (2008). Intersectional invisibility: The distinctive advantages and disadvantages of multiple subordinate-group identities. Sex Roles, 59, 377-391 
Phinney, J. S. (1990). Ethnic identity in adolescents and adults: A review of research. Psychological Bulletin, 108, 499-514.

Quintana, S. M., Chao, R. K., Cross, W. E., Hughes, D., Gall, S. N. L., Aboud, F. E., ... Vietze, D. L. (2006). Race, ethnicity, and culture in child development: Contemporary research and future directions. Child Development, 77(5), 1129-1141.

Richards, G. (1997). Race, racism, and psychology: A reflexive history. London: Routledge.

Rosenthal, L. (2016). Incorporating intersectionality into psychology: An opportunity to promote social justice and equity. American Psychologist, 71(6), 474-485.

Rosenthal, L., \& Levy, S. R. (2010). The colorblind, multicultural, and polycultural ideological approaches to improving intergroup attitudes and relations. Social Issues and Policy Review, 4(1), 215-246.

Rowley, S. J., \& Camacho, T. C. (2015). Increasing diversity in cognitive developmental research: Issues and solutions. Journal of Cognition and Development, 16(5), 683-692.

Santos, C. E., Menjívar, C., VanDaalen, R. A., Kornienko, O., Updegraff, K. A., \& Cruz, S. (in press). Awareness of Arizona's immigration law SB 1070 predicts classroom behavioural problems among Latino youths during early adolescence. Ethnic and Racial Studies.

Schwartz, S. J., Lilienfeld, S. O., Meca, A., \& Sauvigné, K. C. (2016). The role of neuroscience within psychology: A call for inclusiveness over exclusiveness. American Psychologist, 71(1), 52.

Sgoutas-Emch, S., Baird, L., Myers, P., Camacho, M. Lord, S. (2016). We're Not All White Men: Using a Cohort/Cluster Approach to Diversify STEM Faculty Hiring, Thought \& Action, 32, 91-107.

Shweder, R. A. (2000). The psychology of practice and the practice of the three psychologies. Asian Journal of Social Psychology, 3(3), 207-222. 
Stanley, C. A. (2006). Faculty of Color: Teaching in Predominantly White Colleges and Universities. Bolton, MA: Anker Publishing.

Sternberg, R. J. (2016). “Am I famous yet?” Judging scholarly merit in psychological science: An introduction. Perspectives on Psychological Science, 11(6), 877-881.

Suarez-Orozco, C. \& Suarez-Orozco, M.M. \& Todora, I. (2010). Learning a new land: Immigrant students in American society. Cambridge: Belknap Press.

Sue, S. (1999). Science, ethnicity, and bias: Where have we gone wrong? American Psychologist, $54,1070-1077$.

Syed, M. (2016). Power and agency in conceptualizing life stages as master narratives. Human Development, 59, 317-323.

Syed, M. (2017). Why traditional metrics may not adequately represent ethnic minority psychology. Perspectives on Psychological Science.

Syed, M., \& Ajayi, A. A (in press). Promises and pitfalls in the integration of intersectionality with development science. In C. E. Santos \& R. B. Toomey (Eds.), Envisioning the Integration of an Intersectionality Lens in Development Science: New Directions for Child and Adolescent Development. San Francisco: Jossey-Bass.

Toomey, R. B., Huynh, V. W., Jones, S. K., Lee, S., \& Revels-Macalinao, M. (2017). Sexual minority youth of color: A content analysis and critical review of the literature. Journal of Gay \& Lesbian Mental Health, 21(1), 3-31.

Umaña-Taylor, A. J., Quintana, S. M., Lee, R. M., Cross, W. E., Rivas-Drake, D., Schwartz, S. J., \& ... Seaton, E. (2014). Ethnic and racial identity during adolescence and into young adulthood: An integrated conceptualization. Child Development, 85(1), 21-39.

U.S. Department of Education, National Center for Education Statistics. (2016). The Condition of Education 2016 (NCES 2016-144), Characteristics of Postsecondary Faculty. 
U.S. Department of Education, National Center for Education Statistics. (2016). Digest of Education Statistics, 2015 (NCES 2016-014), Chapter 3.

U.S. Department of Education, National Center for Education Statistics. (2016). The Condition of Education 2016 (NCES 2016-144), Characteristics of Postsecondary Faculty.

van Hoof, A. (1999). The identity status field re-reviewed: An update of unresolved and neglected issues with a view on some alternative approaches. Developmental Review, 19(4), 497-556.

Verkuyten, M. \& Yildiz, A.A. (2007). National (dis)identification and ethnic and religious identity: A study among Turkish-Dutch Muslims. Personality and Social Psychology Bulletin, 33, 1448-1462.

Whaley, A. L. (2009). Stereotype threat paradigm in search of a phenomenon: A comment on Kellow and Jones’s (2008) study. Journal of Black Psychology, 35(4), 485-494.

Whiteman, S. D., McHale, S. M., \& Crouter, A. C. (2011). Family relationships from adolescence to early adulthood: Changes in the family system following firstborns’ leaving home. Journal of Research on Adolescence, 21(2), 461-474.

Winston, A. S. (Ed.). (2004). Defining difference: Race and racism in the history of psychology. Washington, DC: American Psychological Association.

Yoo, H. C., \& Pituc, S. (2013). Assessments of perceived racial stereotypes, discrimination, and racism. In K. F. Geisinger (Ed.), APA handbook of testing and assessment in psychology (pp. 427-451). Washington, DC: American Psychological Association.

Zosuls, K. M., Ruble, D. N., Tamis-LeMonda, C. S., Shrout, P. E., Bornstein, M. H., \& Greulich, F. K. (2009). The acquisition of gender labels in infancy: implications for gender-typed play. Developmental Psychology, 45(3), 688-701. 